\title{
Methodology to evaluate acoustic performance in educational spaces by Different Methods
}

\author{
Pro.Dr.Ahmed Abd-Alwahab Rezk ${ }^{\mathrm{a}}$, Pro. Dr. Huda Soliman Sideak ${ }^{\mathrm{b}}$, Dr. Hosny Ahmed Dewar , \\ Dr. Mahmoud Muhamed Abd-Alrazik, Eng. Rania Abdo Aly-Aldean .

\footnotetext{
${ }^{a}$ Architecture Professor and Environmental design Architecture department, Tanta University, ${ }^{\mathrm{b}}$ Professor, Building Physics Institute Acoustic Department, (HBNC) c Lecturer of Architecture, Architecture department, Tanta University, ${ }^{\mathrm{d}}$ Lecture, Building Physics Institute, (HBNC), ${ }^{\mathrm{e}}$ Architecture department, Tanta University.
}

\begin{abstract}
Different methodologies used to evaluate acoustic performancein in educational lecture hall. Theses technical methods have been used in order to define the acoustic problems in lecture hall and suggest acoustic and architecture treatments to solve these acoustic problems. The methods that used for acoustic analysis were Sabin, Eyring, Arau-puchades and ODEON. This paper is foucing on acoustic performance in lecture hall 2 in Tanta Engineering. Acoustic study has been done for lecture hall as follows: Evaluation the acoustic performance by field measurements for reverberation time, manual calculation and acoustic simulation; ODEON software. Different acoustic performance analysis was performed. Different acoustic and architecture treatments were suggested based on the analysis. The final results of room acoustics of different cases carried on the hall were compered to the international requirements for educational spaces. The main problems based on the acoustic analysis are the increase of hall height, architecture design of ceiling and hard covering of the internal surfaces
\end{abstract}

Keywords: ODEON, Acoustic Performance, Reverberation Time, Acoustic Treatments, Acoustic simulation, ODEON, field measurments.

\section{INTRODUCTION}

$\Lambda$ coustic measuring and simulation are very important to determine acoustic performance and acoustic comfort in spaces.Computer simulations to predict acoustical parameters have been attracting renewed interest in recent years. New technologies for acoustic simulations and measurements have been developed, and it is now possible to predict and measure the acoustics of a room with good accuracy ${ }^{\mathrm{i}}$.

There are many acoustic software programs in room we will use ODEON because, it cares acoustic side only in first step. It gives complete impression of acoustic performance in space, and results are given out in both graphical representations and tables. It gives most important criteria in space acoustics are usually reverberation time (RT) by (Sabin, Eyring and Arau-puchades) and speech transmission index (STI), early reflection in room (C50), sound pressure level (SPL), sound transmission class (STC) in this study we will foucse on RT ${ }^{\mathrm{ii}}$.

Acoustic measurements are the obvious prerequisite of acoustic investigations; they are an important tool for the analysis of acoustical problems. Acoustics of educational spaces (classrooms, lecture halls or speech rooms and auditoria) engross the attention of the researchers in this field in the past years. Thus, researches in this field has been going $\mathrm{n}$ over the years with the aim of enhancement acoustic performance in educational spaces in universities through studying the most important factors affecting the acoustics performance in educational spaces is relation between RT and space hall. We will calculate RT for one of education spaces by manual equation, field measurement, and simulation by software, and compare final results of reverberation time (RT) with RT require for educational spaces ${ }^{\text {iii }}$.

We scope this study on main lecture hall 2 in engineering faculty, Tanta University, it located in ground floor of college building (Workshop building), Engineering faculty, Sebrbay colleges' campus, next to Workshop spaces and main quad it`s known Eadady Modarg figure (1). 
1. Preparatory

Building, Department of

Electrical powers

And Administration

2. Architecture

Department and

Administration

3. Library, Mechanical

Power Department, Math

And Physics Department

4. Building and

Construction Building

5. Civil Department

6. Workshops

7. Lecture hall $1 \& 2$

(Case study)

8. Main arene.

9. Green Area.

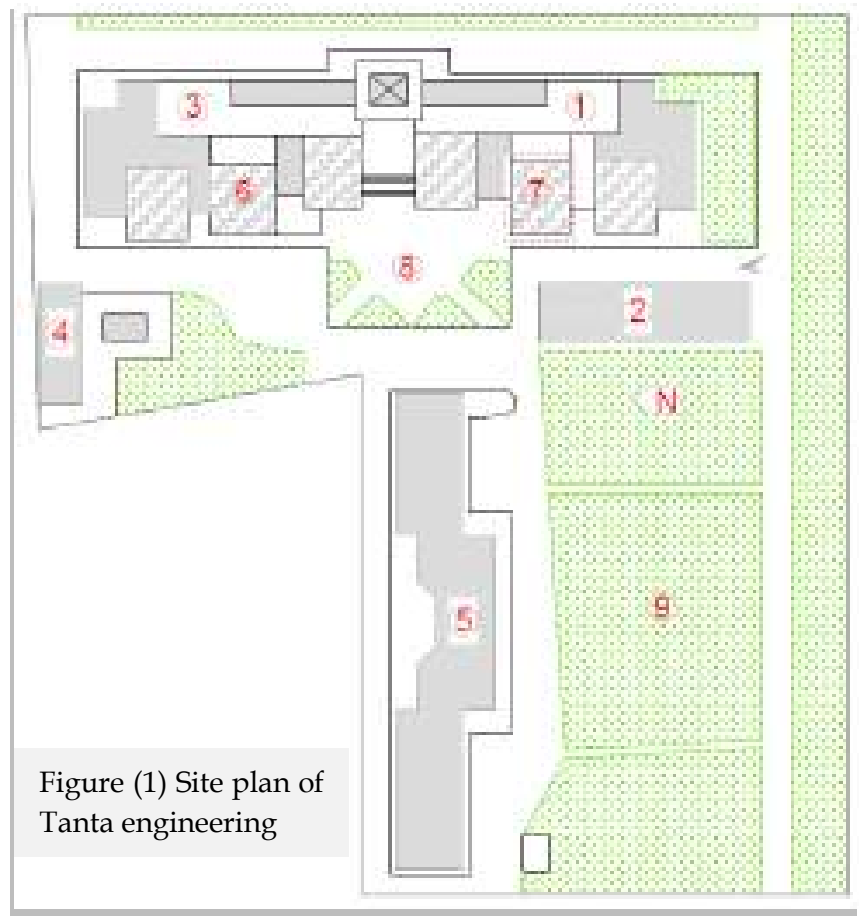

Table (1) Description of Lecture hall 2

Dimensions

$\begin{array}{cllrc}\mathbf{L} & \mathbf{W} & \mathbf{H} & {\text { Area } \mathbf{~ m}^{2}}^{2} & \text { Volume } \mathbf{~ m}^{3} \\ 29.7 \mathbf{m} & 19.3 \mathrm{~m} & 10.6 \mathbf{m} & 573.2 & 6076\end{array}$

Statistical Data

Desks 19 wooden row, with $1 \mathrm{~m}(\mathrm{~W}), 1 \mathrm{~m}(\mathrm{H}), 10 \mathrm{~cm}$ the row higher from row previous.

Stage, concrete, $2.65 \mathrm{~m}(\mathrm{~W}), 13.10(\mathrm{~L})$, The distance to first row $2.35 \mathrm{~m}$.

Hall is divided into 6 modules, width of each about $5 \mathrm{~m}$.

Interior surface are covered up with hard finishing, ceiling has skylight in each hall.

Sound system, amplifier, microphone and 8 loudspeakers, 4 at each side

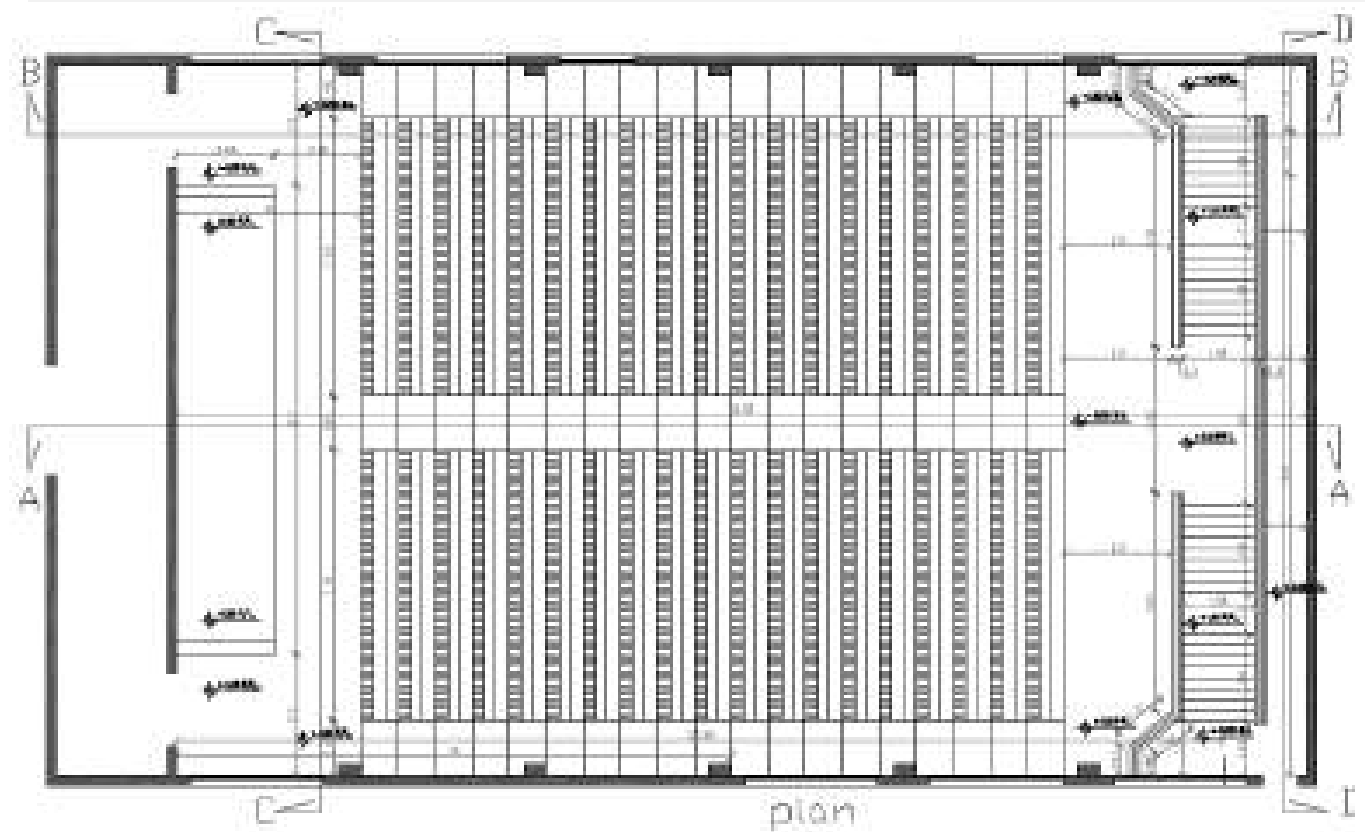




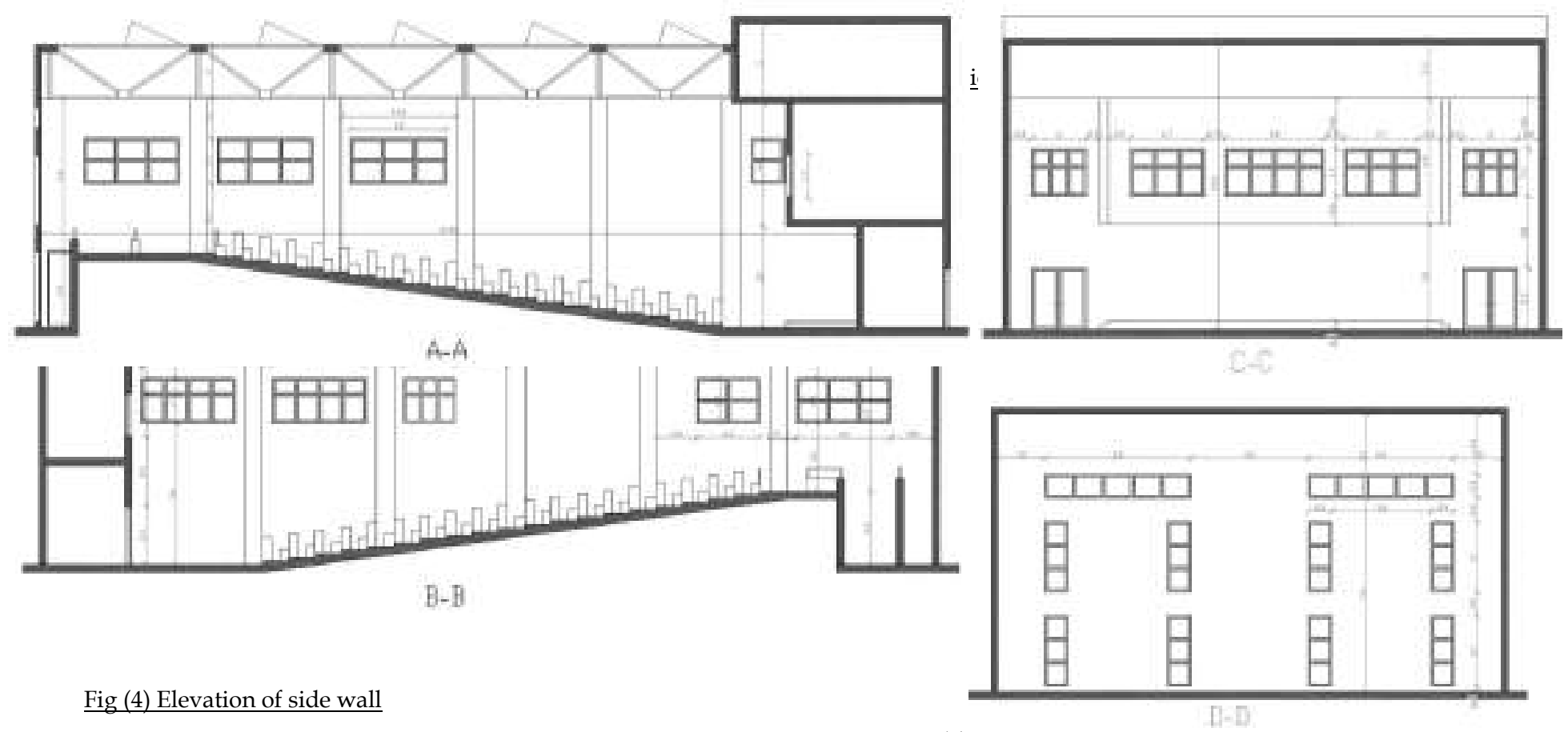

$\underline{\text { Fig (5) Elevation of side wall } \quad \text { Fig (6) Elevation of tront wall }}$

$\underline{\text { Fig (7) Elevation of rear wall }}$

\section{2- Methodology}

a- Selection case study.

b- Architecture describe for case study.

c- Calculate requirement RT for case study by equation.

d- Done field measurement by devices in case study.

e- Evaluation basic case from field measurement results.

f- Entering architecture data for case study in acoustic software simulation.

g- Done acoustic simulation for case study model.

h- Evaluation basic case from acoustic software simulation results.

i- Calabrat acoustic software program and compare RT results by manual equation, field measurement, and acoustic program simulation.

j- Determin acoustic problems in case study.

k- Suggestion acoustic and architecture treatments

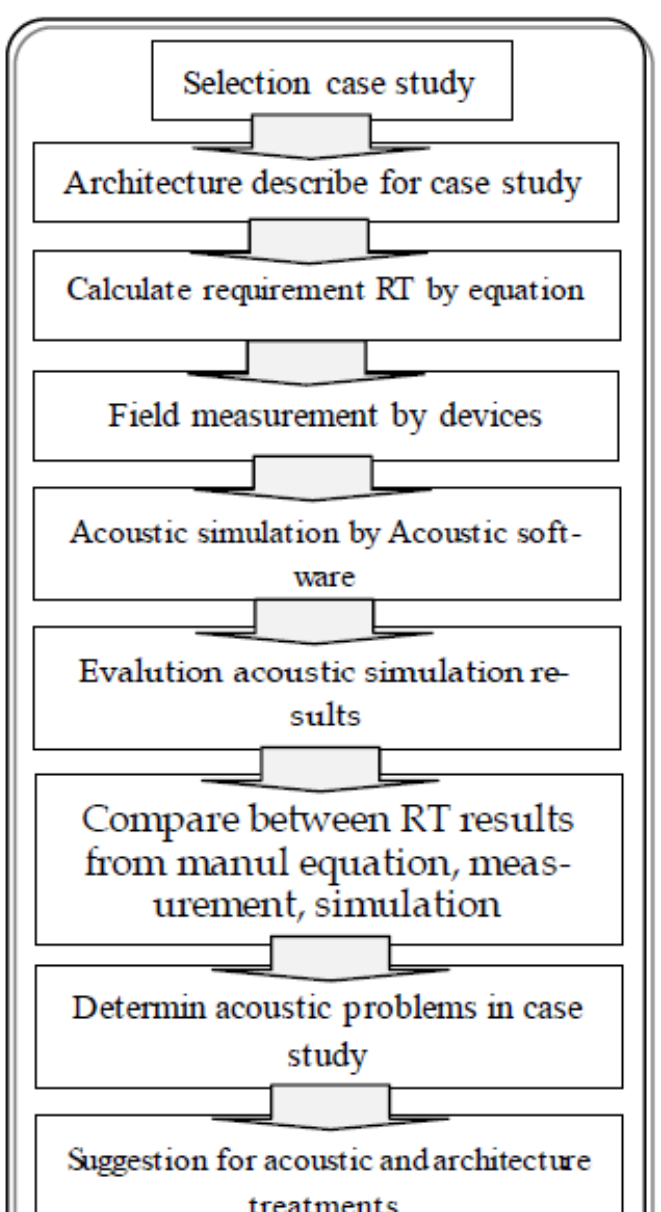




\subsection{RT by Manual equation}

In previous paragraph we selected case study and architecture describe then determine requirement reverberation time for hall from equation

$$
\mathrm{TR}=[0.32 * \lg (\mathrm{V})-0.17] \mathrm{s}, \quad,(\mathrm{V}) \text { space size, }
$$

Whereas TR depends on space volume, required reverberation time is based on furnished occupied areas. When unoccupied TR, should no more than $0.2 \mathrm{~s}$ over required time. (Vary $\overline{2} 0 \%$ in frequency range $250 \mathrm{~Hz}$ to 2000 $\mathrm{Hz}$ ).the figure shown chart of Requirement reverberation time range for speech spaces ${ }^{4}$.

Table (2) for RT require values at differnat frequency

\begin{tabular}{|l|l|c|c|c|c|c|c|}
\hline & $\begin{array}{l}\mathbf{1 2 5} \\
\text { HZ }\end{array}$ & $\begin{array}{l}\mathbf{2 5 0} \\
\text { HZ }\end{array}$ & $\begin{array}{c}\mathbf{5 0 0} \\
\text { HZ }\end{array}$ & $\mathbf{1 0 0 0}$ & $\mathbf{2 0 0 0}$ & $\mathbf{4 0 0 0}$ & $\mathbf{8 0 0 0}$ \\
\hline RT requirement & 1.48 & 1.05 & 1 & 1 & 1 & 1 & 1 \\
\hline
\end{tabular}
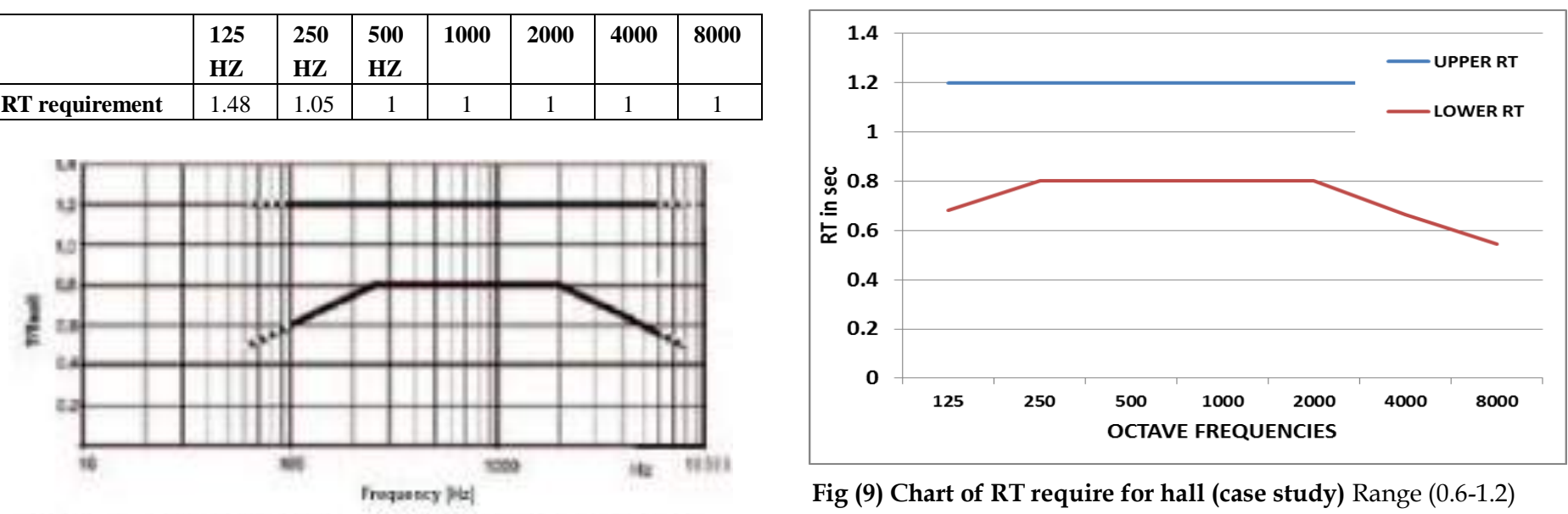

Fig (9) Chart of RT require for hall (case study) Range (0.6-1.2)

The frequency dependire RT IReverheration Timel ronge for speech.

\subsection{RT by Field measurement for basic case}

Acoustic measurements are main prerequisite of acoustic investigations. In this research measurements depend on reverberation time measured, it is done through following:

1- Used Devices: there are a lot of types of acoustic measuring equipment but in this research we use Hand-held Analyzer Type $2270(\mathrm{~B} \& \mathrm{~K})$ is use with connection of condenser microphone type 4189 $(B \& K)$ and omnidirectional loudspeaker type $4292(B \& K)$ with power amplifier $2716(B \& K)$. Using the reverberation time Software BZ-7227.

2- Work Method: analyzer generates noise test signal and excites the space of the room through third octave filtered noise signal figure (11). The reverberation time measured in different points through the room at the seating area figure (10). The reverberation time measured using white or pink noise at $1 / 3$ octave band from 125 to $8000 \mathrm{~Hz}$. And calculate the average reverberation time for measurements in space.
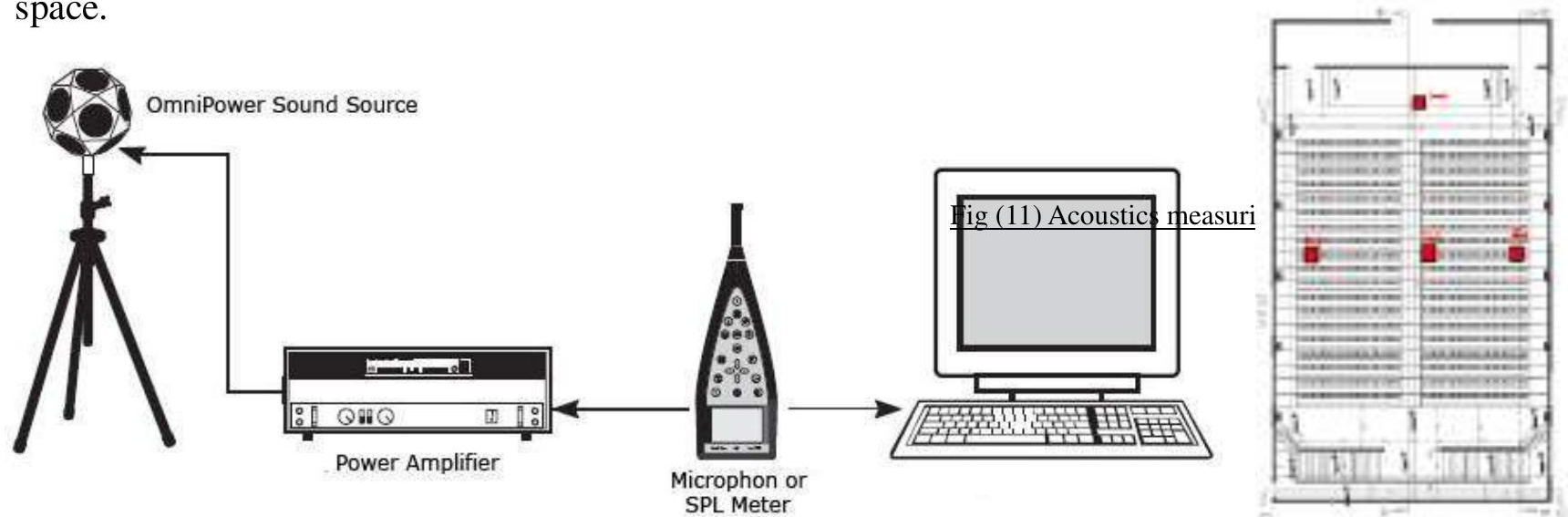


\begin{tabular}{|c|c|c|c|c|c|}
\hline \multicolumn{2}{|c|}{ Freq.HZ } & $\begin{array}{c}\text { point } \\
1\end{array}$ & $\begin{array}{l}\text { point } \\
2\end{array}$ & $\begin{array}{l}\text { Point } \\
3\end{array}$ & $\begin{array}{c}\text { Point } \\
4\end{array}$ \\
\hline \multirow{6}{*}{$\begin{array}{l}\text { Re- } \\
\text { of }\end{array}$} & 125 & 3.44 & 3.64 & 4.75 & 3.4 \\
\hline & 250 & 4.44 & 3.76 & 3.66 & 3.11 \\
\hline & \multicolumn{3}{|c|}{$\mathbf{5 i g}_{10)}$ Poift5 For Rever 3 Bera } & 3.98 & 3.8 \\
\hline & \multicolumn{3}{|c|}{ 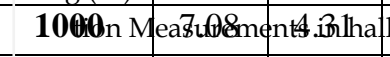 } & 4.8 & 4.17 \\
\hline & 2000 & 3.8 & 3.63 & 3.59 & 3.26 \\
\hline & 4000 & 2.32 & 2.83 & 2.34 & 2.34 \\
\hline & 8000 & 1.4 & 1.33 & 1.24 & 1.31 \\
\hline
\end{tabular}

2.2.1.

sults

field

meas-

ments ure-

Table (3) Reverberation time measurements at 4 points in hall

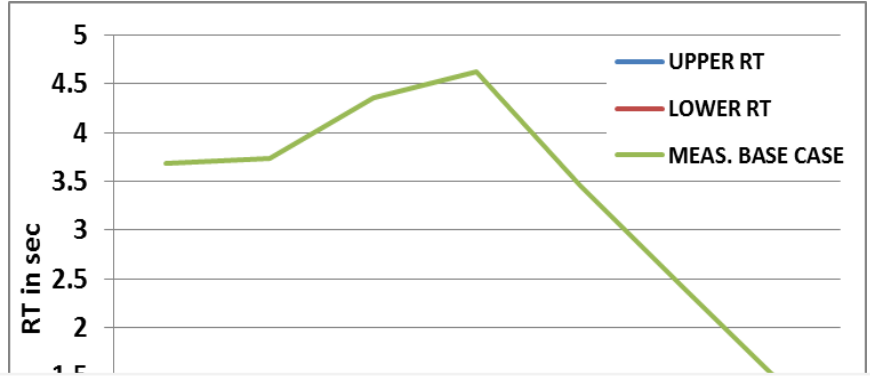

Fig (12) Chart shows relation between Reverberation Time measured in hall So, RT is biggest value at $1000 \mathrm{HZ}$. And RT require

0

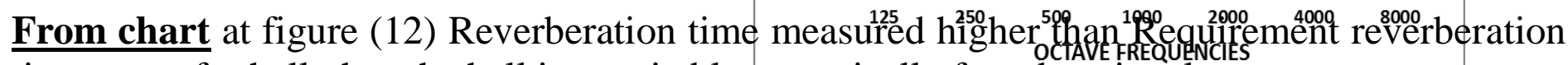
time range for hall, thus the hall is unsuitable acoustically for educational process.

\subsection{RT by Computer software simulation for basic case}

We evaluate basic case acoustically by ODEON software version 9.2, and calibrate program, acoustic simulation at 3 point in different places, this is through several stages:

1- ODEON software

2- Create hall model and entering acoustic data

3- Simulation for hall acoustic performance

4- Results

5- Calibrate

\subsubsection{Results of acoustic hall (BASICE CASE) by ODEON At receives 1, 2, 3}

- Table (4) shown results of acoustic parameters RT

\begin{tabular}{|c|c|c|c|c|c|c|c|c|}
\hline \multicolumn{9}{|c|}{ T30(s)sim } \\
\hline Rec. no. & 63 & 125 & $250^{\mathrm{A}}$ & ersog & 1000 & 2000 & 4000 & 8000 \\
\hline 1 & $63 \mathrm{~A}^{3} \mathrm{z}^{3}$ & $135^{4}$ & $230^{5}$ & $5 \mathbf{8 0}^{3} \mathbf{0}^{77}$ & $1000^{3}$ & $2000^{8}$ & $4000^{6}$ & 8006 \\
\hline 2 & 3.61 & 3.89 & 4.13 & 4.29 & 5.05 & 4.35 & 2.33 & 1.19 \\
\hline 330(s) & 3.65 & 37.87 & 3.898 & $4 \$ .93$ & 4.9 .93 & 4.9.9. 55 & 2.5 .62 & 1.4 .4 \\
\hline
\end{tabular}

- Table (5) shown results average of acoustic parameters

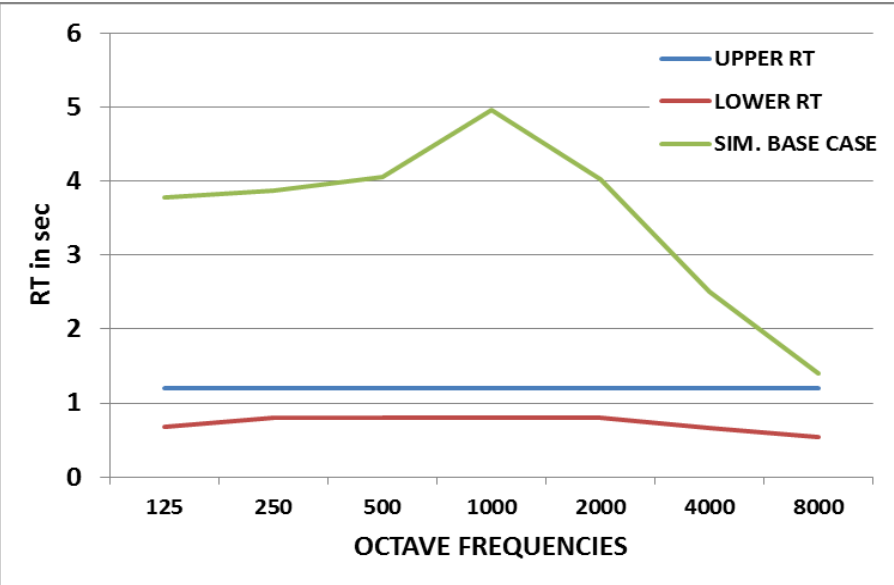


From chart figure (13) Reverberation time simulated higher than Requirement reverberation time range for hall, thus the hall is unsuitable acoustically for educational process.
Fig (13) Chart shows relation between Reverberation Time simulted in hall so; RT is biggest value at $1000 \mathrm{HZ}$. And RT require

\subsection{R T by Sabin, Eyring, Arau-puchades}

From figure (14) RT is higher than Requirement reverberation time range for hall

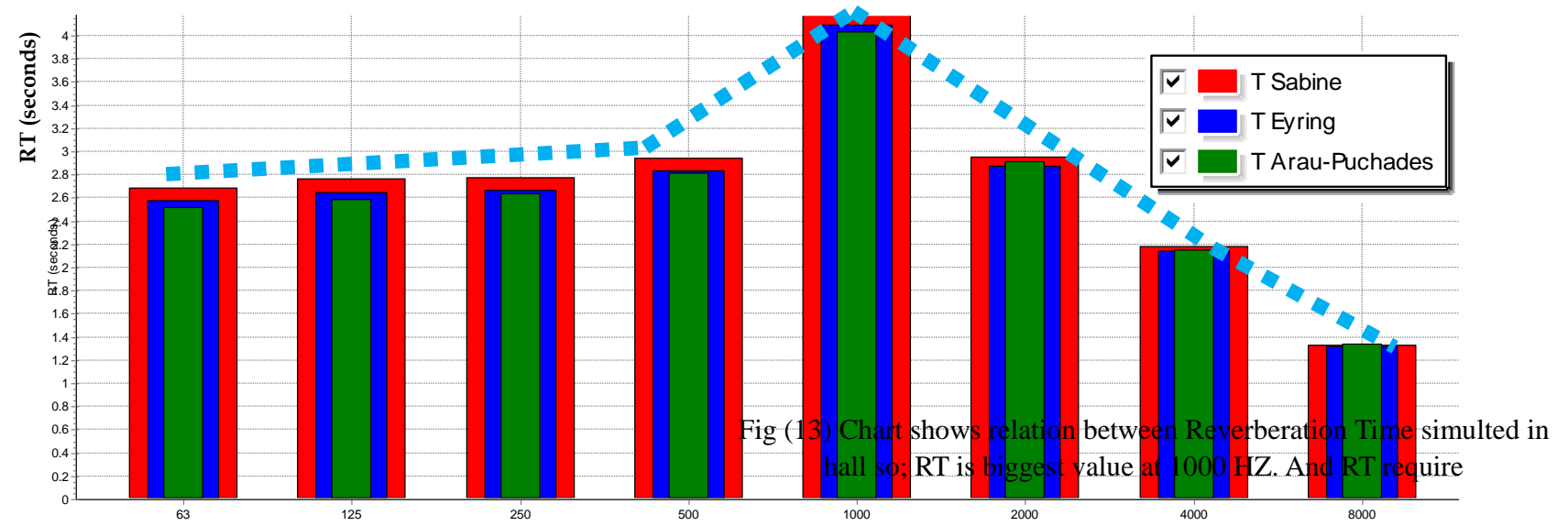

Figure (14) shows RT by Sabin, Eyffrm, chart figure $(13)$ Reverberation tFmequsinqulfted higher than Requirement reverberation time range for hall, thus the

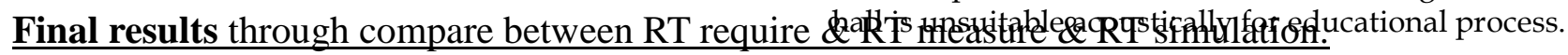

- $\quad$ Table (6) shows RT values (requirement, measurement, simulation)

\begin{tabular}{|cccccccc|}
\hline & $\mathbf{1 2 5}$ & $\mathbf{2 5 0}$ & $\mathbf{5 0 0}$ & $\mathbf{1 0 0 0}$ & $\mathbf{2 0 0 0}$ & 4000 & 8000 \\
\hline RT requirement & 1.48 & 1.05 & 1 & 1 & 1 & 1 & 1 \\
\hline RT average (Measuring) & 3.68 & 3.73 & 4.36 & 4.62 & 3.46 & 2.4 & 1.36 \\
\hline RT average (Simulation) & 3.78 & 3.87 & 4.06 & 4.97 & 4.03 & 2.5 & 1.4 \\
\hline
\end{tabular}

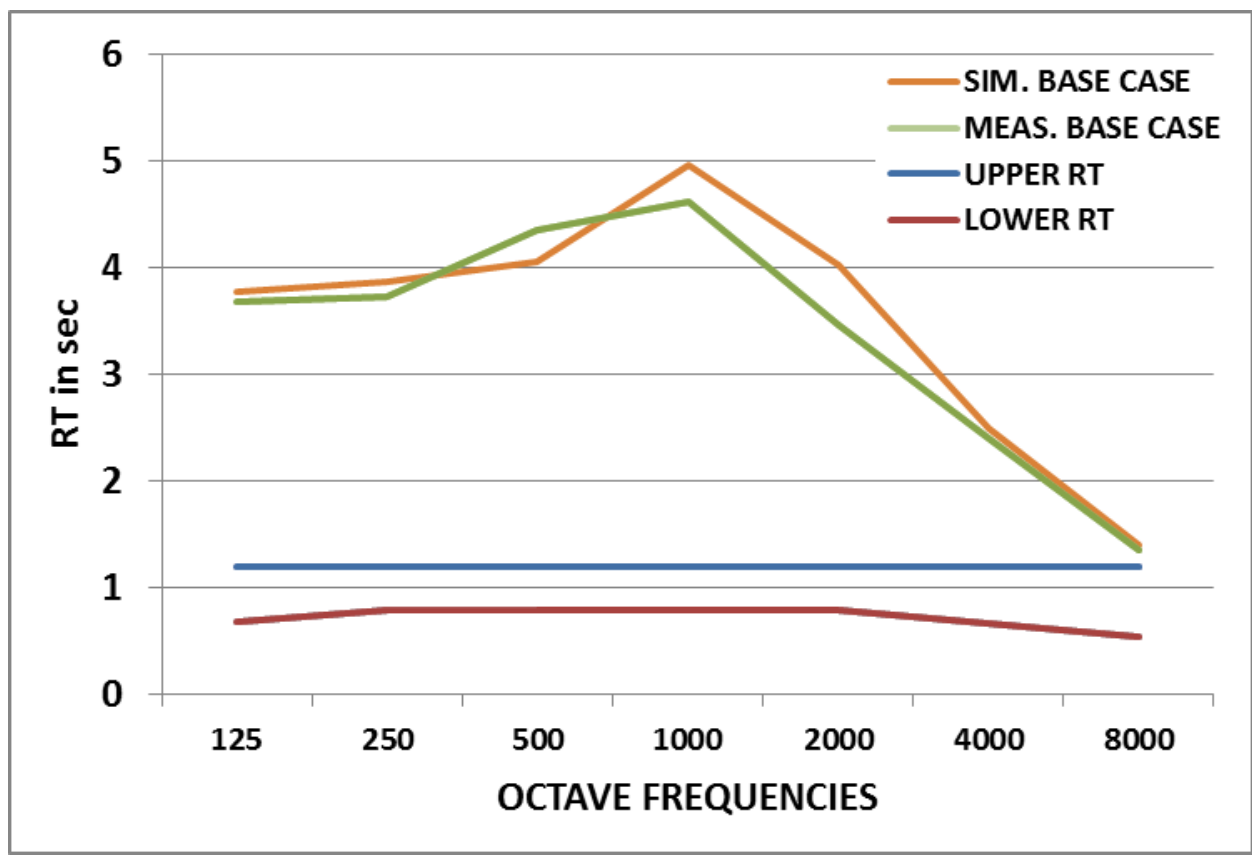

Fig (15) Chart shows relation between $\mathrm{RT}_{143}$ alues for (requirement, measurement, and simulation) 


\section{From chart in figure (15)}

- There is no high difference between RT mea \& RT sim, thus the program was calibrated,

- RTmeasure \& RTsimulate are higher than RTrequire.

- The hall is acoustically unsutable and has acoustic problems.

- The hall needs acoustic and architecture treatments to solve acoustic problems and enhancement acoustic performance in it..

\section{Conclution}

Methodology to evaluate acoustic performance in universities`educational spaces and selecation acoustic problems to suggeste acoustic and architecture treatments to solve this determined problems.

\section{Acknowledgement}

Im thankful to alla then my doctors, Pro. Dr. Ahmed Rizk, Pro.Dr. Huda sideak, Dr. Hosny Dewar, Dr. Mahmud Abd-Alrazikfor for supporting and helping me.

\section{Referances}

Martín. R. S, Arregui. A, Machín. J and Arana. M, "Comparison of Measured and Simulated Room Acoustic Parameter Values Using High Resolution Grids" Acoustics Australia, 2014.

${ }^{1}$ Ying Ye, Qifan Fu, "Studies on the Accuracy of Acoustic Simulation based on EASE Software", IEEE, 2014.

${ }^{1}$ Mahdavi.A, Kainrath, B, Orehounig. K, Lechleitner, J, "Measurement and Simulation of Room Acoustics Parameters in Traditional and Modern Bath Buildings", Build Simul (2008).

${ }^{1}$ DIN 18041 - Room Acoustic- 